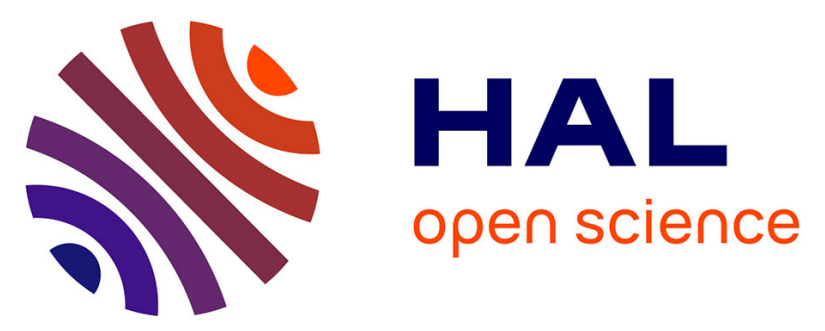

\title{
An Improved Efficiency of Fuzzy Sliding Mode Control of Permanent Magnet Synchronous Motor for Wind Turbine Generator Pumping System
}

Fateh Benchabane, Abdenacer Titaouine, Ouafae Bennis, Abderazak Guettaf, Khaled Yahia, Djamel Taibi

\section{To cite this version:}

Fateh Benchabane, Abdenacer Titaouine, Ouafae Bennis, Abderazak Guettaf, Khaled Yahia, et al.. An Improved Efficiency of Fuzzy Sliding Mode Control of Permanent Magnet Synchronous Motor for Wind Turbine Generator Pumping System. Applied Solar Energy, 2012, 48 (2), pp.112-117. 10.3103/S0003701X12020089 . hal-00744007

\section{HAL Id: hal-00744007 https://hal.science/hal-00744007}

Submitted on 22 Oct 2012

HAL is a multi-disciplinary open access archive for the deposit and dissemination of scientific research documents, whether they are published or not. The documents may come from teaching and research institutions in France or abroad, or from public or private research centers.
L'archive ouverte pluridisciplinaire HAL, est destinée au dépôt et à la diffusion de documents scientifiques de niveau recherche, publiés ou non, émanant des établissements d'enseignement et de recherche français ou étrangers, des laboratoires publics ou privés. 


\title{
An Improved Efficiency Of Fuzzy Sliding Mode Control Of Permanent
}

\section{Magnet Synchronous Motor For Wind Turbine Generator Pumping System}

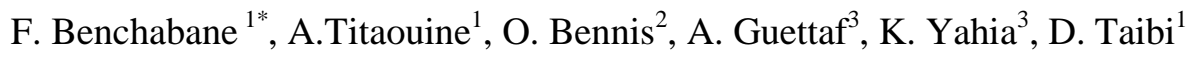 \\ ${ }^{1}$ MSE Laboratory, University of Biskra, B.P.145, 07000, Biskra, Algeria \\ ${ }^{2}$ PRISME Institute, University of Orléans, 21 rue Loigny La Bataille, 28000 Chartres, France \\ ${ }^{3}$ GEB Laboratory, University of Biskra, B.P.145, 07000, Biskra, Algeria \\ * fateh benchabane@yahoo.fr
}

\begin{abstract}
This paper presents an analysis by which the dynamic performances of a permanent magnet synchronous motor (PMSM) motor is controlled through a hysteresis current loop and an outer speed loop with different controllers. The dynamics of the wind turbine pumping drive system with (PI) and a fuzzy sliding mode (FSM) speed controllers are presented. In order to optimize the overall system efficiency, a maximum power point tracker is also used. Simulation is carried out by formatting the mathematical model for wind turbine generator, motor and pump load. The results for such complicated and nonlinear system, with fuzzy sliding mode speed controller show improvement in transient response of the PMSM drive over conventional PI. The effectiveness of the FSM controller is also demonstrated.
\end{abstract}

Key words-- Wind energy system; Permanent magnet synchronous motor; Speed control; Fuzzy; Sliding Mode.

\section{INTRODUCTION}

As a result of increasing environmental concern, more and more electricity is generated from renewable energy. The main advantage of electricity generation from renewable sources is the absence of harmful emission and the infinite availability of the prime mover that is converted to electricity [1, 2]. One of the best ways of generating electricity from renewable energy is to use wind turbines. A tendency to erect more and more wind turbines can be observed in power industry. Wind energy technology has developed extremely rapidly and many commercial wind turbines in the market have a capacity of $2 \mathrm{MW}$ or more. Also the cost of wind-generation electricity has fallen steadily. Wind turbines in USA produce about $1 \%$ of total generation [1]. Also, wind power meets $3 \%$ of the total electricity demand in Europe [1,3], and this development will continue to grow in coming years. It seems that in the near future wind turbines may start to influence the behavior of electrical power systems. As a result of such developments, extensive research is being carried out on the subject of wind generation.

Early studies have concentrated on ways of sizing, matching and adapting wind turbine generator pumping systems since a proper match between the installed capacities with the insolated load is essential to optimize such installations. Various studies have been done on the choice of the drive system, which suits wind turbine_source, types of pumps to use and ways to control and optimize the whole system [4, 5]. This was firmly related to the existing technologies. At the early stage, only DC motors were used to drive pumps. Direct coupling of series, shunt, and separately exited DC motor Wind Turbine Generator pumping systems were studies $[6,7]$. It was found that the overall performances are totally different from those obtained when these motors are connected to a constant voltage source.

Recent implementation showed that the PM motors are well suited for wind turbine generator pumping [8, 9]. They feature high level dynamics, fast response, and high efficiency which lend them naturally pumping systems mainly for low power.

It is well known that conventional PI controller is the most widely used in industrial applications due to its simple control structure, easy design and low cost. However, it suffers from lower response, oscillation and larger overshoot.

The design of fuzzy sliding mode controllers is still practically performed with trial and error method which has prevented a wide diffusion of system controllers based on fuzzy set theory. Therefore, fuzzy sliding mode controllers are specially designed to control problems of non-linear, non stationary or ill-defined systems.

This paper presents a study for optimal operation of a PMSM motor for wind turbine generator pumping system under its non linear and complicate model with hysteresis current controller and different controllers PI: classical proportional-integral and fuzzy sliding mode controllers.

\section{WIND TURBINE MODEL}

Figure 1 shows the wind turbine induction generator system configuration considered in this study. The wind energy generation system consists of a horizontal axis turbine connected to a cage-machine rotor through a gear system. The induction machine is driven at supersynchronous speed and it feeds a constant impedance load at a terminal voltage, $V_{d c}$. The models for the different components of the wind turbine-generator system are given in the following subsections.

The output power of a wind turbine is a complex relationship involving the wind speed $(\mathrm{Vw})$, expressed as $[1$, 10, 11]:

$$
\mathrm{P}_{\mathrm{m}}=\frac{1}{2} \rho \mathrm{A} \cdot \mathrm{C}_{\mathrm{p}} \cdot \mathrm{V}_{\mathrm{w}}^{3}
$$

$\rho$ is the air density, A is the swept area by the blades. The power coefficient $\mathrm{Cp}$ is a function of the tip speed ratio, $\lambda$, which is the ratio of linear speed at the tip of blades to the speed of wind, expressed as

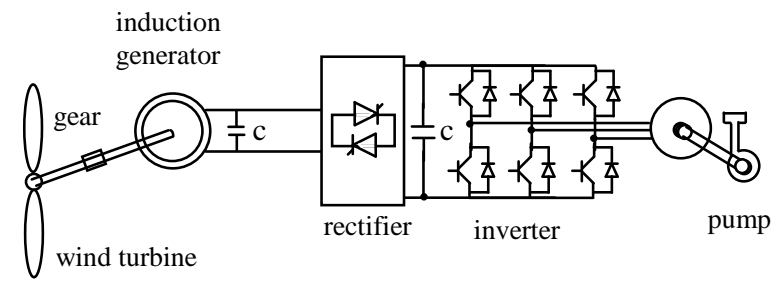


Figure.1. The wind turbine-generator system

$$
\lambda=\frac{\Omega \mathrm{R}}{\mathrm{V}_{\mathrm{w}}}
$$

$\mathrm{R}$ is the radius, $\Omega$ is the mechanical angular velocity, respectively, of the wind turbine rotor. Expressions of $\mathrm{Cp}$ as a function of $\lambda$ employed in $[1,12,13]$ are:

$$
\begin{aligned}
\mathrm{C}_{\mathrm{p}}(\lambda) & =7.9563 .10^{-5} \lambda^{+5}-17.375 .10^{-4} \lambda^{+4}-9.86 .10^{-3} \lambda^{+3} \\
- & 9.41 .10^{-3} \lambda^{+2}+6.38 .10^{-2} \lambda+0.001
\end{aligned}
$$

Typical $\mathrm{Cp}-\lambda$ curves for the pitch angle equal zero as shown in Figure 2.

Figure 3 shows the power-speed characteristics curves of a typical wind turbine for various wind velocities.

\section{PMSM MODEL}

The electrical and mechanical equations of the PMSM in the rotor reference $(\mathrm{d}-\mathrm{q})$ frame are as follows $[14,15,16]$ :

$$
\left[\begin{array}{c}
\mathrm{V}_{\mathrm{d}} \\
\mathrm{V}_{\mathrm{q}}
\end{array}\right]=\left[\begin{array}{cc}
\mathrm{R}_{\mathrm{s}} & -\mathrm{L}_{\mathrm{q}} \omega \\
\mathrm{L}_{\mathrm{d}} \omega & \mathrm{R}_{\mathrm{s}}
\end{array}\right]\left[\begin{array}{c}
\mathrm{I}_{\mathrm{d}} \\
\mathrm{I}_{\mathrm{q}}
\end{array}\right]+\left[\begin{array}{cc}
\mathrm{L}_{\mathrm{d}} & 0 \\
0 & \mathrm{~L}_{\mathrm{q}}
\end{array}\right] \frac{\mathrm{d}}{\mathrm{dt}}\left[\begin{array}{c}
\mathrm{I}_{\mathrm{d}} \\
\mathrm{I}_{\mathrm{q}}
\end{array}\right]+\omega \cdot \phi_{\mathrm{f}}\left[\begin{array}{l}
0 \\
1
\end{array}\right]
$$

Figure 4, presents the model of PMSM in d-q axis.

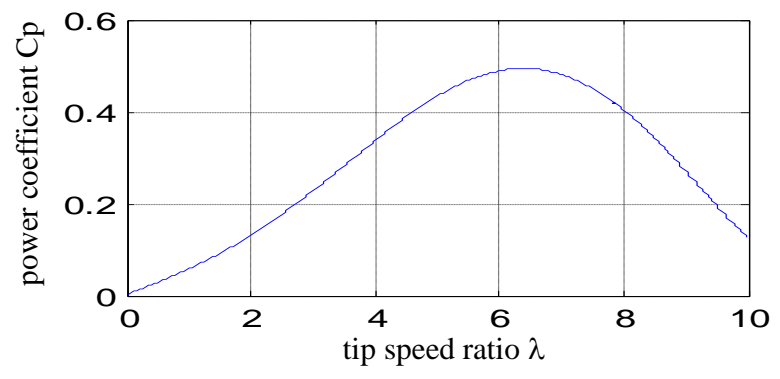

Figure.2. Typical power coefficient - tip speed ratio plot.



Figure.3. Speed $\mathrm{V}_{\mathrm{s}}$. power output characteristics of a wind turbine.



Figure.4. model of PMSM in d-q axis

The electromagnetic torque $\mathrm{T}_{\mathrm{e}}$ is given by:

$$
\mathrm{T}_{\mathrm{e}}=\mathrm{p}\left(\left(\mathrm{L}_{\mathrm{d}}-\mathrm{L}_{\mathrm{q}}\right) \mathrm{I}_{\mathrm{d}} \cdot \mathrm{I}_{\mathrm{q}}+\Phi_{\mathrm{f}} \cdot \mathrm{I}_{\mathrm{q}}\right)
$$

And the equation for the motor dynamic, on the other hand is

$$
\mathrm{T}_{\mathrm{e}}-\mathrm{T}_{1}=\mathrm{J} \frac{\mathrm{d} \Omega}{\mathrm{dt}}
$$

\section{FUZZY SLIDING MODE CONTROL OF THE PMSM}

\section{IV.1. Sliding mode controller design}

The advantages of the sliding mode controller can be summarized as follows [17]:

1) Fast response with no overshoot.

2) No steady state error.

3) Robustness, stability in a closed loop environment, insensitivity to parameter variations and load disturbances.

The switching patterns for a six-pulse inverter are generated directly by the sliding mode. The SMC is designed in $\mathrm{d}-\mathrm{q}$ plane, and the voltages $\mathrm{V}_{\mathrm{d}}^{*}, \mathrm{~V}_{\mathrm{q}}^{*}$, are taken as control inputs. The following switching hypersurfaces are used:

$$
\begin{aligned}
& S_{1}=I_{d r e f}-I_{d} \\
& S_{2}=I_{q r e f}-I_{q}
\end{aligned}
$$

with $\mathrm{I}_{\mathrm{dref}}=0$.

These selections are based on the concept of vector control and instantaneous current control [17,18]. and are related to inner loop (current loop). In this case, the current components $I_{d}$ and $I_{q}$ are decoupled. The reference currents $I_{\text {dref }}$ and $I_{\text {qref }}$ are determined by the outer loop.

The control inputs are taken as follows:

$$
\begin{aligned}
& \mathrm{V}_{\mathrm{d}}^{*}=\mathrm{K}_{\mathrm{d}} \operatorname{sign}\left(\mathrm{S}_{1}\right) \\
& \mathrm{V}_{\mathrm{q}}^{*}=\mathrm{K}_{\mathrm{q}} \operatorname{sign}\left(\mathrm{S}_{2}\right)
\end{aligned}
$$

the gains $\mathrm{K}_{\mathrm{d}}, \mathrm{K}_{\mathrm{q}}$ are selected so as to satisfy the existence condition of the sliding mode:

$$
\lim _{S_{\mathrm{i}} \rightarrow 0} \mathrm{~S}_{\mathrm{i}} \dot{S}_{\mathrm{i}}<0, \mathrm{i}=1,2
$$

Which is equivalent, using the Lyapunov stability, to:

$$
\mathrm{V}=\sum_{\mathrm{i}=1}^{2} \mathrm{~V}_{\mathrm{i}}
$$

with

$$
\mathrm{V}_{\mathrm{i}}=\frac{1}{2} \mathrm{~S}_{\mathrm{i}}^{2}
$$

Then, for the control system to be stable, the time derivative of (12) must be negative, i.e. 


$$
\mathrm{V}=\sum_{\mathrm{i}=1}^{2} \mathrm{~S}_{\mathrm{i}} \dot{\mathrm{S}}_{\mathrm{i}}<0
$$

$\mathrm{K}_{\mathrm{d}}$ selection: Hence, if we chose $\mathrm{K}_{\mathrm{d}}$ as

$$
\mathrm{K}_{\mathrm{d}}<-\max _{\mathrm{I}_{\mathrm{q}}, \omega}\left|\mathrm{L}_{\mathrm{q}} \mathrm{I}_{\mathrm{q}} \omega\right|
$$

which yields the following inequality

$$
\mathrm{S}_{1} \dot{\mathrm{S}}_{1}<-\frac{\mathrm{R}_{\mathrm{s}}}{\mathrm{L}_{\mathrm{d}}} \mathrm{S}_{1}^{2}<0
$$

Only the information about the boundaries of $\mathrm{I}_{\mathrm{q}}$ and $\omega$ is needed before designing the SMC.

$\mathrm{K}_{\mathrm{q}}$ selection: Hence, we chose $\mathrm{K}_{\mathrm{q}}$ as

$$
\mathrm{K}_{\mathrm{q}}<-\max _{\mathrm{I}_{\mathrm{q}}, \omega}\left|\mathrm{R}_{\mathrm{s}} \mathrm{I}_{\mathrm{q}}+\mathrm{L}_{\mathrm{q}} \dot{\mathrm{I}}_{\mathrm{q}}+\phi_{\mathrm{f}} \omega\right|
$$

which yields the following inequality

$$
\mathrm{S}_{2} \dot{\mathrm{S}}_{2}<-\frac{\mathrm{R}_{\mathrm{s}}}{\mathrm{L}_{\mathrm{q}}} \mathrm{S}_{2}^{2}<0
$$

Only the information about the boundaries of $\mathrm{I}_{\text {qref }}$ and $\omega$ is needed before designing the SMC.

\section{IV.2. Fuzzy logic controller}

The general structure of a complete fuzzy control system is given in figure 5 . The plant control $\mathrm{u}$ is inferred from the two state variables, error (e) and change in error $\Delta \mathrm{e}[19,20]$.

The actual crisp inputs are approximates of the closer values of the respective universes of discourse. Hence, the fuzzyfied inputs are described by singleton fuzzy sets.

The design of this controller is based on the phase plan. The control rules are designed to assign a fuzzy set of the control input for each combination of fuzzy sets of and $[19,20]$.

Table 1 shows one of possible control rule base. The rows represent the rate of the error change e and the columns represent the error (e) . Each pair (e,e) determines the output level NB to PB corresponding to $\mathrm{u}$.

Here NB is negative big, NM is negative medium, $\mathrm{ZR}$ is zero, $\mathrm{PM}$ is positive medium and $\mathrm{PB}$ is positive big, are labels of fuzzy sets and their corresponding membership functions are depicted in figures 6, 8 and 8, respectively. The continuity of input membership functions, reasoning method, and defuzzification method for the continuity of the mapping $\mathrm{u}_{\text {fuzzy }}(\mathrm{e}, \mathrm{e})$ is necessary. In this paper, the triangular membership function, the max-min reasoning method, and the center of gravity defuzzification method are used, as those methods are most frequently used frequently in the literature [18]



Figure. 5. The structure of a fuzzy logic controller.

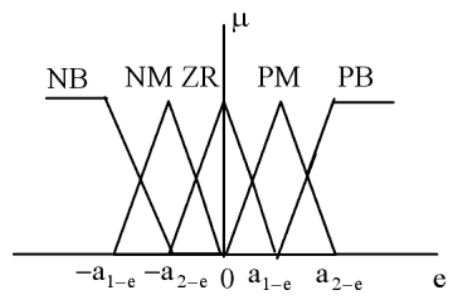

Figure. 6. Membership functions for input e .

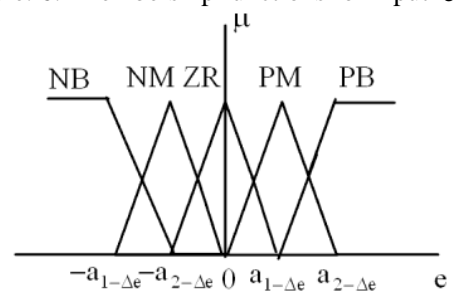

Figure. 7. Membership functions for input $\Delta \mathrm{e}$.

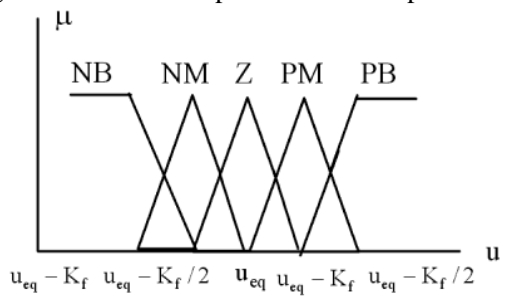

Figure. 8. Membership functions for output $u$.

\begin{tabular}{|c|c|c|c|c|c|c|}
\hline \multirow{2}{*}{\multicolumn{2}{|c|}{$\mathrm{D}_{\mathrm{u}}$}} & \multicolumn{5}{|c|}{$\mathrm{DE}_{\mathrm{n}}$} \\
\cline { 3 - 7 } \multicolumn{2}{|c|}{} & $\mathrm{NB}$ & $\mathrm{NM}$ & $\mathrm{ZR}$ & $\mathrm{PM}$ & $\mathrm{PB}$ \\
\hline \multirow{5}{*}{$\mathrm{E}_{\mathrm{n}}$} & $\mathrm{NB}$ & $\mathrm{NB}$ & $\mathrm{NB}$ & $\mathrm{NM}$ & $\mathrm{NM}$ & $\mathrm{ZR}$ \\
\cline { 2 - 7 } & $\mathrm{NM}$ & $\mathrm{NB}$ & $\mathrm{NM}$ & $\mathrm{NM}$ & $\mathrm{ZR}$ & $\mathrm{PM}$ \\
\cline { 2 - 7 } & $\mathrm{ZR}$ & $\mathrm{NM}$ & $\mathrm{NM}$ & $\mathrm{RZ}$ & $\mathrm{PM}$ & $\mathrm{PM}$ \\
\cline { 2 - 7 } & $\mathrm{PM}$ & $\mathrm{NM}$ & $\mathrm{ZR}$ & $\mathrm{PM}$ & $\mathrm{PM}$ & $\mathrm{GP}$ \\
\cline { 2 - 7 } & $\mathrm{PB}$ & $\mathrm{ZR}$ & $\mathrm{PM}$ & $\mathrm{PM}$ & $\mathrm{GP}$ & $\mathrm{GP}$ \\
\hline
\end{tabular}

Table. 1. Rules Base for speed control.

\section{PUMP MODEL}

The pump used is of centrifugal type which can be described by an aerodynamic load which is characterised by the following load equation $[1,5]$ :

$$
\mathrm{T}_{1}=\mathrm{A} \omega^{2}
$$

where $\mathrm{A}$ is the pump constant.

\section{SIMULATION RESULTS}

\section{Simulation Results of Wind turbine-generator system}

Using fourth order Runge-Kutta numerical resolution method under Matlab, the overall system shown in Figure 9 was simulated. The system was first simulated without the hysteresis current controller and speed controllers. Once this last is reached, the flux and Vdc reference values are applied. These are: $\phi_{\mathrm{r}-\mathrm{ref}}=0.8 \mathrm{~Wb} ; \mathrm{v}_{\mathrm{dc}-\mathrm{ref}}=515 \mathrm{v}$.

Figure 10 show a wind turbine-generator system characteristics, the generator output stator current $i_{\text {abc }}$, the stator voltage $V_{a b c}$ and DC voltage $V_{d c}$, we can see that the generated voltage reache the reference one with high precision. The DC voltage is controlled with the torque via the current isq.

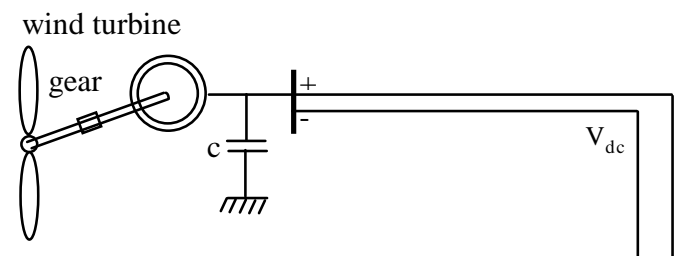


Figure.9. Overall system configuration.
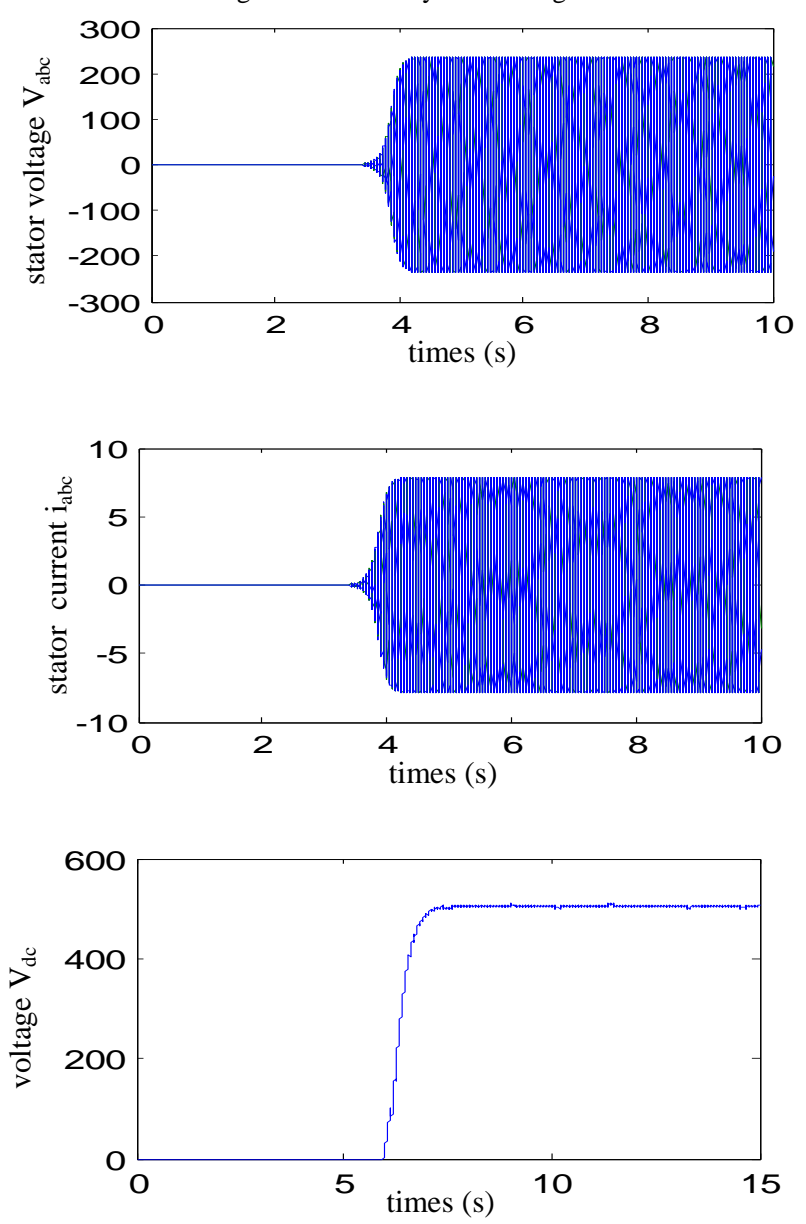

Figure.10. Simulation results for wind turbine-generator system

\section{Simulation Results Of Fuzzy Sliding Mode Control Of PMSM Fed By Wind Turbine Generator}

After, the speed and current regulations are introduced, results are shown in Figure 11 (regulation with PI controller) and Figure 12 (regulation with fuzzy sliding mode controller) the response current and torque ripples are distinctly reduced, the speed following the reference with overshot in PI controller.

To illustrate performances of control, we simulated a loadless starting up mode with the reference speed +100 $\mathrm{rad} / \mathrm{s}$ at time $10 \mathrm{~s}$ and an application of the load torque $\left(\mathrm{C}_{\mathrm{r}}=5\right.$
$\mathrm{Nm}$ )at time $12 \mathrm{~s}$. We can notice the good performances of the fuzzy sliding mode control; the real speed converges to the reference one with a high precision. The electromagnetic torque allure is presented, it can concluded that the electromagnetic torque developed by the motor increased at $t$ $=12 \mathrm{~s}$ to $5 \mathrm{Nm}$ for compensate the load torque.

This figure demonstrates the perfect decoupling between the $\mathrm{d}$ and $\mathrm{q}$ axis. The $\mathrm{d}$ stator current conserved a constant value while $\mathrm{q}$ stator current followed the increasing and the decreasing of electromagnetic torque. These results demonstrate the good performances of the regulation.

So with fuzzy sliding mode controller, the speed converges to the reference value very quickly without any overshot and with zero steady state error. It is shown that the proposed drive with fuzzy sliding mode controller is also capable of following the reference speed at best time response, zero steady state error and almost without any overshot.
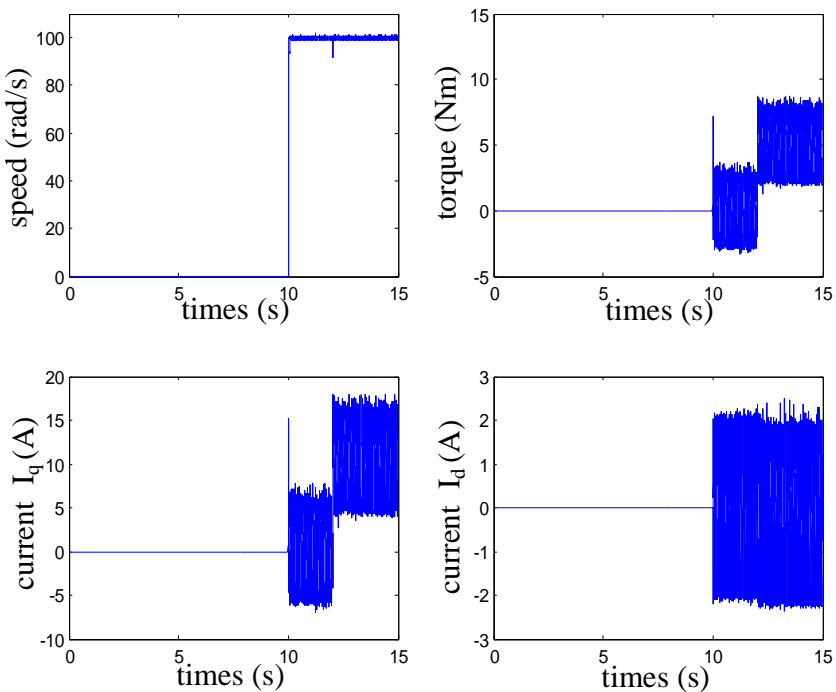

Figure.11. Simulation results with PI speed and hysteresis current controllers regulation under loading condition
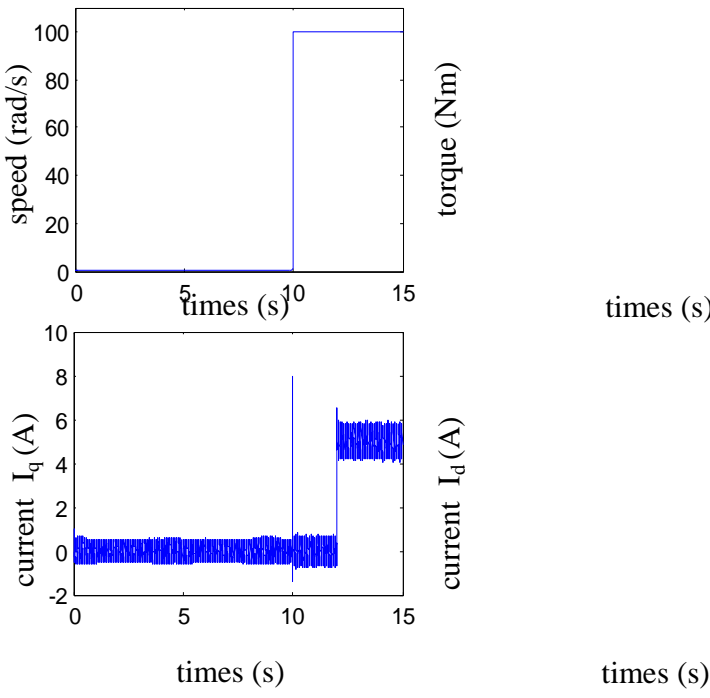



Figure.12. Simulation results with fuzzy sliding mode speed controllers regulation under loading condition

\section{CONCLUSION}

The performances of fuzzy sliding mode controller applied to the PMSM motor connected to wind turbine generator and driving a centrifugal pump is investigated. The wind turbine generator system was first studied without regulation then with a hysteresis controller and two types of speed controllers: classical PI and nonlinear (fuzzy sliding mode) under loading conditions. The dynamic behaviours of the drive system with both controllers were presented and compared. It was proved that for such complicated and nonlinear control system, the fuzzy sliding mode controller ensures much better dynamical properties.

The fuzzy sliding mode control of the permanent magnet synchronous motor used as charge presents a good performance of regulation of speed. We can say that the associations of the wind turbine and induction generator permits feeding the PMSM with a sufficient voltage and frequency.

\section{APPENDIX}

Parameters of the system used in simulation:

Parameters of the turbine:

$\mathrm{R}=3.36 \mathrm{~m}$

$\rho=1.225 \mathrm{~kg} / \mathrm{m}^{3}$

$\mathrm{V}_{\mathrm{w}}=6 \mathrm{~m} / \mathrm{s}$

Parameters of the Induction generator:

$$
\begin{aligned}
& \mathrm{R}_{\mathrm{s}}=1.2 \Omega ; \mathrm{R}_{\mathrm{r}}=1.8 \Omega ; \mathrm{L}_{\mathrm{s}}=0.115 \mathrm{H} ; \mathrm{L}_{\mathrm{r}}=0.115 ; \\
& \mathrm{J}=0.07 \mathrm{Kg} . \mathrm{m}^{2} ; \mathrm{f}_{\mathrm{r}}=0.001 \mathrm{Nm} . \mathrm{s} / \mathrm{rad} ; \\
& \mathrm{p}=1 ; \Omega=314 \mathrm{Rad} / \mathrm{s} .
\end{aligned}
$$

Parameters of the PMSM:

Rated power $1 \mathrm{Kw}$

Rated speed $3000 \mathrm{rpm}$

Stator winding resistance $0.6 \Omega$

Stator winding direct inductance $4 \mathrm{mH}$

Stator winding quadrate inductance $2.8 \mathrm{mH}$

Rotor flux $0.12 \mathrm{~Wb}$

Viscous friction 1.4 e-3 Nm/rad/s

Inertia 1.1 e- $3 \mathrm{~kg} \mathrm{~m} 2$
Pairs pole number 4

Nominal current, voltage line 20 A, $310 \mathrm{~V}$

Machine type: Siemens 1FT6084-8SK71-1TGO

Parameters of the PWM converter:

Supply's voltage and frequency: $220 \mathrm{~V}(\mathrm{rms}), 50 \mathrm{~Hz}$

Line's inductor and resistance $0.002 \mathrm{H}, 0.08 \Omega$

Output capacitors $0.0025 \mathrm{~F}$

PWM carrier frequency $1 \mathrm{kHz}$

\section{REFERENCES}

[1] A.Guettaf, A. Betka, O. Bennis, Direct field oriented control of induction motor fed by wind turbine generator under saturation effect, Mediterranean Journal of Measurement and Control, Vol. 7(01), 2011, pp. 190-196.

[2] J.G. Slootweg, H. Polinder, W.L. Kling, Dynamic modeling of a wind turbine with doubly fed induction generator, Proc. IEEE Conf. On Power Eng Soc Summer Meeting, 2001, pp. 644-649.

[3] A.H.M.A. Rahima, M. Ahsanul Alam, M.F. Kandlawala, Dynamic performance improvement of an isolated wind turbine induction generator, Computers and Electrical Engineering, Vol. 35, 2009, pp. 594-607.

[4] D.C. Seyoum, M.F. Rahman, The dynamic characteristics of an isolated self-excited induction generator driven by a wind turbine, Proc. IEEE Conf. On Industrial Electronics, 2003, pp. 936-944.

[5] A. Terki, A. Moussi, A. Betka, an improved efficiency of fuzzy logic control of pmbldc for pv pumping system, Applied Mathematical Modelling, Vol. 36, 2012, pp. 943-944.

[6] E.S. Abdin, W. Xu, Control design and dynamic performance analysis of a wind turbine-induction generator unit, IEEE Transactions on Energy Conversion, Vol. 15, 2000, pp. 91-96.

[7] A. Causebrook, D.J. Atkinso, Fault ride-through of large wind farms using dynamic breaking resistors", IEEE Transactions Power System, Vol. 22, 2007, pp. 966-975.

[8] C. Chompoo-inwai, Y. Chitra, K. Methaprayoon, "Reactive compensation techniques to improve the ride-through of induction generators during disturbance", Proc. IEEE Conf. On IAS Annu Meeting, 2004, pp. 2044-2050.

[9] M. Karari, W. Rosehart, Comprehensive control strategy for a variable speed cage machine wind generator unit, IEEE Transactions on Energy Conversion, Vol. 20, 2005, pp. 415-423.

[10] K. Idjdarene, D. Rekioua, T. Rekioua, Vector control of autonomous induction generator taking saturation effect into account, Energy Conversion and Management, Vol. 49, 2008, pp. 2609-2617.

[11] D. Rekioua, T. Rekioua, T. Rekioua, An approach for the modeling of an autonomous induction generator taking into account the saturation effect, Int J Emerg Elect Power Syst, Vol. 4, 2005, pp. 1-23.

[12] V. Calderaro, C. Cecati, A. Piccolo, Adaptive Fuzzy Control for Variable Speed Wind Systems with Synchronous Generator and Full Scale Converter, Green Energy and Technology, Vol. 0, 2010, pp. 337-366.

[13] D. Seyoum, C. Grantham, Terminal voltage control of a wind turbine driven isolated induction generator using stator oriented field control, IEEE Transactions on Industrial Electronics, 2003, pp. 846-852.

[14] A. Titaouine, A. Moussi, Sensorless nonlinear control of permanent magnet synchronous motor using the extended kalman filtre, Asian Journal of Information Technology, Vol. 5 , 2006, pp. 1416-142.

[15] F. Benchabnae, A. Titaouine, Sensorless control strategy for permanent magnet synchronous motor fed by ac/dc/ac converter, Proc. IEEE Conf. On Electrical Machines, 2010, pp. 1-6.

[16] A. Titaouine, F. Benchabane, Application of Ac/Dc/Ac converter for sensorless nonlinear control of permanent magnet synchronous motor, Proc. IEEE Conf. Systems, Man and, 2010, pp. 2282-2287.

[17] M.T.Benchouia, S.E. Zouzou, A. Golea, A. Ghamri, A.Modeling and simulation of variable speed system with adaptive 
fuzzy controller application to PMSM, IEEE International Conference on Industrial Technology ICIT, Vol. 2 (2004) 683-687. [18] F. Benchabane, A. Titaouine, O. Bennis, Systematic fuzzy sliding mode approach combined with extended Kalman filter for permanent magnet synchronous motor control, Mediterranean Journal of Measurement and Control, Vol. 7(01), 2011, pp. 183189.

[19] F. Benchabane, A. Titaouine, O. Bennis, Sliding mode control of permanent magnet synchronous motor fed by wind turbine generator taking saturation effect into account, Proc. IEEE Conf. On Electric Machines and Power Electronics \& Electromotion Joint Conference, 2011.

[20] M. Vilathgamuwa, M.A. Rahman, K.J. Tseng, Non-linear control of interior permanent magnet synchronous motor, Proc. IEEE Conf. Industry Applications Conference, 2000, pp. 11151120. 